\title{
SCHOOL HEALTH IN THE SERVICES
}

\author{
Lieutenant Colonel J. G. P. POWER, \\ M.B., B.Cंh., D.P.H., D.I.H., D.T.M. \& H., R.A.M.C. \\ Headquarters, Land Forces, Hong Kong
}

IN England and Wales the education, health and welfare of school children is covered by the Education Act of 1944 and the National Health Service Act of 1946; similar legislation exists in Scotland. Overseas, including in this context B.A.O.R., the Services assume the duties of Local Education and Local Health Authorities and the United Kingdom legislation is deemed to apply to service school children.

In the Army, School Health Services have been developed and school doctors and school nurses (S.S.A.F.A. sisters usually) have been appointed to most schools. Army Health specialists co-ordinate and administer school health work on behalf of senior administrative medical officers.

This paper is based on three years' experience in B.A.O.R. and Hong Kong, which in addition to the organisation and administration of school health schemes, included direct participation as a school doctor. Since at least half the service populations in most overseas stations nowadays consist of dependants the need for school health services is unquestioned. There are large numbers of children at school between the ages of four and a half and fifteen years and appreciable numbers in the sixteen to nineteen years age bracket. The Army provides large numbers of day schools and a smaller total of boarding premises.

\section{The aims of a school health service}

The primary aim in school health work is to foster the health of all children at school so that they may derive the maximum benefit from the education provided and may eventually leave school better equipped to undertake the responsibilities of adult life. A secondary aim is to provide a counselling service for parents and an advisory service for teachers. The Chief Medical Officer of the Department of Education and Science (1964) stated:

"The school health service could not exist without, and should not seek to be independent of, the services which provide by far the greater part of treatment for all age groups in the population. Its future development lies in close partnership with these services. It is essentially a preventive health service for children at school and the prevention or limitation of disability requires the closest association with general health services".

Medical officers and S.S.A.F.A. sisters who participate in school health work are usually deeply involved in family health generally, and thus a basis for integration with the general health services provided for service personnel and their families already exists. Essentially, school health work must always be approached from a preventive medicine angle, which takes full account of personal and environmental factors. An obvious example is the child with defective vision, who in addition to wearing corrective spectacles, must be placed in a well lighted classroom, so that he can see the blackboard clearly. The achievement of this aim requires co-operation between the school doctor, the ophthalmic specialist and the class teacher. 


\section{School medical examinations}

The first and most important requirement in school health is a system of health screening by which " at risk" children are pinpointed and those with defects which require attention are referred for specialist investigation and remedial treatment if necessary.

\section{Selective screening}

A selective system of medical examination was adopted by the Services some years ago, similar to schemes in common practice in many Local Education Authority schools in the United Kingdom. The prevailing general good health and improved social circumstances no longer justify the old system of periodic medical examination of all children, irrespective of real need. Doctors' time, which could be spent more profitably in dealing with those children who have serious handicaps, personal problems and emotional and educational difficulties, must not be wasted.

It is an advantage that most school medical officers in the Services are also family doctors and can deal with the school child's problems in the context of the general family background as well as in that of school health. Perhaps it is a disadvantage that the training and orientation of most service doctors who carry out school medical officer duties is directed largely towards curative rather than preventive medicine. The value of school medical examination is not only the recognition of the relatively few children who need investigation and possibly remedial treatment, but also as a basis on which to assure the parents of fit and well children (the majority) and their teachers, that they should be able to gain full benefit from the education provided.

Williams (1966) described a comprehensive, detailed and time-consuming method of examination aimed at pinpointing " at risk" school children which placed considerable emphasis on the taking of a history. Bearing in mind that only about one in every ten children examined will require investigation, this method is not recommended as a general screening measure.

\section{Questioñnaires}

Peters (1965) has devised an expanded form of questionnaire designed to facilitate medical examination. A similar type is now being used in schools in Hong Kong. Peters (1966) in a personal communication discussed the merits and disadvantages of questionnaires generally. In service schools, these, if properly devised, should have real value because they will be completed by parents who are accustomed to form-filling and who can be persuaded to reply without much difficulty. Properly designed questionnaires may be of value also to medical officers whose approach to school health is different to that of the full time school medical officer.

\section{The School Nurse}

The role of the S.S.A.F.A. sister is most important in selective medical examination. Her assistance, since she is highly qualified and orientated towards preventive medicine, is invaluable. Her duties should include preliminary vision testing and the measurement of heights and weights. She should screen the completed questionnaires and if necessary consult individual parents on specific problems. Finally, she should always be present with the doctor during medical examinations and should assist in documentation, with special attention to children referred to hospital for specialist investigations. 


\section{Results}

The results of medical examinations carried out over one year are shown in Table I, in respect of 12 schools with an overall population of approximately 7000 children.

Table I ,

Results of medical examinations in the year 1965/66

\begin{tabular}{l|c|c|c|c|c}
\hline $\begin{array}{c}\text { Age } \\
\text { (Years) }\end{array}$ & $\begin{array}{c}\text { School } \\
\text { entry }\end{array}$ & $\begin{array}{c}\text { School } \\
\text { leaving }\end{array}$ & Special & Defects & $\begin{array}{c}\text { Referred to } \\
\text { specialists }\end{array}$ \\
\hline $\begin{array}{l}4 \text { to } 7 \\
8 \text { to } 10\end{array}$ & 606 & & 106 & 83 & 61 \\
$\begin{array}{l}11 \text { to } 14 \\
15 \text { plus }\end{array}$ & & 55 & 51 & 7 & 7 \\
\hline Totals & 606 & 55 & 157 & 107 & 8 \\
\hline Gross total & & 818 & & & 80 \\
\hline
\end{tabular}

Using the selective system 818 (11.6 per cent) of these children were seen by the school doctors and of those examined 107 (13 per cent) were found to have defects, but of the latter only 80 (9.8 per cent) were referred for specialist consultation. On this basis, using the selective system, about one in ten of all school children will require medical examination, This is an average figure and will be higher in certain types of school, for example primary schools accepting children in the age group four and a half to seven years only.

Table II shows that in a primary infants school $96(27.4)$ per cent) were examined in one term, including 75 children starting school for the first time. Of this latter group 15 (20 per cent) were referred to specialists. Table III shows the breakdown of the 18 cases selected for referral.

Table II

Medical examination resultsSpring Term 1967

\begin{tabular}{|c|c|c|c|c|c|}
\hline & & \\
\hline $\begin{array}{c}\text { Age } \\
\text { (Years) }\end{array}$ & $\begin{array}{l}\text { School } \\
\text { entry }\end{array}$ & Special & $\begin{array}{l}\text { Referred to } \\
\text { specialists }\end{array}$ & \multirow{3}{*}{$\begin{array}{l}\text { Visual defects including squint } \\
\text { Speech defects } \\
\text { Ear, nose and throat defects } \\
\text { Dental caries } \\
\text { Orthopoedic defect } \\
\text { Hydrocephalus }\end{array}$} & \multirow{3}{*}{$\begin{array}{r}10 \\
3 \\
2 \\
1 \\
1 \\
1\end{array}$} \\
\hline $\begin{array}{l}4 \text { to } 5 \\
6 \text { to } 7\end{array}$ & 75 & 21 & $\begin{array}{r}15 \\
3\end{array}$ & & \\
\hline Totals & 75 & 21 & 18 & & \\
\hline $\begin{array}{l}\text { Gross } \\
\text { Total }\end{array}$ & \multicolumn{2}{|c|}{$96 \ldots$} & & Total & 18. \\
\hline
\end{tabular}

Table III

Breakdown of the 18 cases referred to specialists

In the writer's view, all school medical examinations should be carried out on the school premises and not in family consulting rooms. Particularly with very young children it is essential to get away from the white coat and clinical atmosphere and to make the medical examination friendly and informal. It is a waste of time to see children in the absence of one parent, especially the mother, since most examinations include 
investigations of parental attitudes to their children and vice versa. The presence of the experienced S.S.A.F.A. sister is invaluable in helping to fill in the family background.

\section{Health education}

Parents have the primary responsibility of teaching their children good personal hygiene habits at home, and teachers must ensure that healthy habits are taught and practised in school. The school doctor and nurse should advise parents on specific aspects of health during medical examinations, while the school nurse can also visit the school at other times for this purpose.

\section{Dental health}

The medical officer should check teeth during medical examinations and refer children to the dentist as necessary. All school children should have regular inspections by a visiting dentist at least once a year and more frequently if possible. If the school doctor or nurse considers that the general dental state in a school is poor, the doctor should request the services of a dentist to screen these children who need treatment.

\section{Immunisation Programmes}

Vaccination requirements in most overseas Commands are more extensive than in the United Kingdom and it is particularly important for school doctors and nurses to advise parents during medical examinations. Due to frequent moves of - service families even the most obvious vaccination requirements may have been neglected, for example DTP boosters at eighteen months to two years, or the DT booster prior to school entry. In Hong Kong a special leaflet has been produced for distribution to each family showing all immunisation requirements from birth to school leaving age. A monthly news letter is circulated to all families and is used as a means of disseminating information on vaccinations as well as on a host of other health topics.

\section{Poliomyelitis vaccination}

This deserves special mention. It is a very simple matter to arrange periodic vaccination campaigns, when teachers in addition to children should be offered oral vaccine.

\section{Heaf testing and $B C G$ vaccination}

Heaf testing of school children should be carried out by age groups to estimate tuberculosis conversion rates. By this means the age groups at greatest risk can be pin-pointed and negative reactors can be offered $B C G$ vaccination.

A large-scale Heaf survey was carried out in the schools in B.A.O.R. referred to in Table I. The distribution of positive reactors was as follows:

$\begin{array}{lr}\text { School entrants ( } 4 \text { to } 5 \text { years) } & 4 \text { per cent } \\ 11 \text { to }-15 \text { years } & 20 \text { per cent } \\ 16 \text { to } 19 \text { years } & 45 \text { per cent }\end{array}$

It was clear that pre-school children were remarkably free from infection; more than half of the Heaf positives had had BCG vaccine in infancy, which meant that less than 2 per cent were natural positive reactors. Following this survey it was agreed that all Heaf negative school children from eleven years upwards should be offered BCG vaccination. 
The problem in Hong Kong is different and a survey will be initiated soon. Since BCG vaccination is advised for children prior to arrival in Hong Kong it will be interesting to see what proportion of negative reactors will be found in the pre-school age group. All babies born in Hong Kong, both in the local population and in the Services, are offered BCG vaccination at birth. There is a very high incidence of tuberculosis in the local Chinese population and many families employ Chinese women as amahs. There are also other means of contact with the local population and taking this and previously mentioned factors into account it will be worth trying to discover the natural conversion rates in the different age groups of school and pre-school children.

\section{BCG Vaccination by Dermo-jet}

During the BCG vaccination campaign in B.A.O.R. a trial of the Dermo-jet versus the usual intradermal method of vaccination was carried out (Power 1967). The Dermojet compared favourably with the intradermal needle and syringe and had a marked advantage in speed and painlessness. Mechanical defects and risks of infection have not been overcome completely. However, the writer is convinced that there is a real future for the Dermo-jet method of BCG vaccination in school children, if not also for a wider range of immunisations, for example measles and small pox, in adults as well as children.

\section{Handicapped school children}

Ascertainment, registration and placement of mentally and physically handicapped children have been developed in the Services and are now most important requirements in every school health service. It is the less obvious degrees of handicap which tend to escape notice, therefore the first essential is an efficient and comprehensive method of screening. The system of school medical examination, which allows more time and concentrates on "at risk" children, is the first line of attack. Children will also come to light through teachers, family doctors, parents, S.S.A.F.A. sisters and others.

\section{Audiometry}

This is a method of screening for the less obvious degrees of deafness and the portable Amplivox has been used by the writer and trained S.S.A.F.A. sisters to screen groups of " at risk" children. Absolute quiet is seldom obtainable in school but the trained operator will overcome this difficulty. The basic requirements of a school audiometric service have been described by Beaver (1965).

\section{Vision testing}

The school nurse can screen all children presenting for medical examination and will be able to select those cases requiring special attention by the school doctor and possible referral to an ophthalmologist. The E test, and the OXO test which uses a few familiar letters, are sufficiently good to screen most illiterate school entrants on whom it is impossible to use Snellen's test types. Colour vision testing using Ishihara plates should be carried out on secondary school entrants.

\section{Ascertainment of mental handicap}

In the United Kingdom there is a statutory responsibility to ascertain and register children who may require special educational treatment (S.E.T.) or special training if ineducable. The Services have accepted this responsibility for children of service families 
residing overseas. Early ascertainment of handicapped children, particularly those mentally backward and/or maladjusted, is of vital importance if success is to be achieved in successful placement on return to the United Kingdom. Service children registered as handicapped have to take their place with those children already on waiting lists for S.E.T. in the various Local Authority areas in the United Kingdom. The method of ascertainment is similar to that used in the United Kingdom, including documentation, and service children are registered with the Institute of Army Education with a view to securing places in special schools.

There is a conflict of desires in many cases, for example the lack of S.E.T. facilities overseas versus the natural wishes of parents to keep the child united with the family, versus the career prospects of the service father. The following case histories illustrate some of the difficulties which occurred in practice in two severely mentally handicapped children. The names are ficticious.

\section{Sammy Smith}

Eleven and a half years old when first registered as probably Severely Sub-normal (SSN) or at best low-grade Educationally Sub-normal (ESN) and recommended as in urgent need of a boarding place in a training centre in the United Kingdom.

The important point in this case is that, although there was reason to suspect that Sammy was an " at risk" child from birth, no really constructive action was initiated until he was over eleven years old. He was a breech presentation delivered by Caesarean section with a birth weight of $6 \mathrm{lb} 9 \mathrm{oz}$; he appeared normal until from one year onwards he started to have convulsions recurring, on average, monthly. His developmental milestones such as sitting, walking and talking were within normal limits but after a few more years of apparently normal development his standards of walking and talking seemed to regress.

At six years of age the first serious attempts at mental assessment were carried out and an IQ (Stanford-Binet) of 71 was obtained; an encephalogram at that time showed diffuse abnormality over both temporal lobes. He was then diagnosed as having suffered brain damage due to birth trauma. IQ tests (Stanford-Binet) carried out subsequently were 49 at age six, 57 at age seven and 56 at age eight years. He had been treated as educable at his first nursery school because of the original IQ assessment of 71 . In retrospect it seems possible that this was inaccurate. In October, 1966 and February, 1967 he was reassessed by an educational psychologist, using the Wechsler Intelligence Scale for Children (W.I.S.C.) as probably SSN, with a reading of less than 46 on the full scale and very little difference in the verbal and performance sections of the test.

Early in 1965 the father was posted overseas and prior to departure he was advised by the Army medical authorities in the United Kingdom not to take the child.

However he did not accept that advice and the overseas medical authorities were warned in advance and requested to provide necessary medical cover. The family remained in the station for two and a half years and it was only near the end of this period that the parents agreed that Sammy should be ascertained formally. He is now on a waiting list for special training in the United Kingdom.

\section{Robert Ryan}

This mongol boy was aged ten years when first ascertained by the writer and found to be S.S.N. and recommended for special training in the United Kingdom. The family 
was resident in B.A.O.R. at this time and two years later Robert was still there with his family. By then he had had four changes of school, during which time little was achieved except to give his mother a break of a few hours during the day from the onerous and stressful task of coping with the boy. Father, an intelligent man, accepted the need for special training, but mother refused to accept fully Robert's limitations. Just before the writer left B.A.O.R. a special place in a day training centre was secured. However, language and cultural differences will hinder real progress and the only true solution to this problem is to return the boy to a training centre in the United Kingdom.

These two cases are described at some length because, although both are extremes of mental backwardness, they illustrate some of the complexities involved in dealing with such cases in service practice overseas. In particular they draw attention to the necessity for early ascertainment with a view to placement in the United Kingdom for S.E.T. before children become too old to benefit. There is a natural reluctance by parents, particularly mothers, to refuse or to be unable to face the fact that their offspring are not normal. It requires effort, patience and tact to persuade such parents that ascertainment should be carried out. Lastly, one must consider the time wasted in the normal school overseas and the extra effort required from school teachers to cope with belowstandard pupils. Remedial classes are only a method of occupying the time of such pupils until they can be returned home.

\section{Child Guidance}

Child guidance services exist now in many overseas Commands but it is not yet clear how best child guidance can be organised in the Services. The static Child Guidance Centre has limited value because of widespread populations and distances involved. Child guidance must really be brought to the schools by visiting psychiatrists, educational psychologists, psychiatric social workers and others. Liaison should be established with teachers, school doctors and Army Health specialists as necessary so that children can be kept under constant surveillance and reviewed periodically to determine future action.

\section{Control of infectious disease}

Poliomyelitis, because of mass vaccination, is rarely a problem nowadays and the common infectious diseases of childhood pose few difficulties. School doctors must know incubation and isolation or surveillance periods and must be realistic in their approach to quarantine of contacts. It is seldom necessary to close a school because of communicable diseases; in fact, in boarding schools, it might be wiser to control epidemics such as influenza or other upper respiratory, or gastro-intestinal infection, by keeping children at school rather than sending them home to disseminate infection through the community.

Taylor (1965) states that, as a generalisation, all children suffering from any infectious disease, and home contacts of smallpox, diphtheria, poliomyelitis and meningitis should be excluded from school and that all other contacts may attend school except the infant school contacts of whooping cough, and in some cases measles.

\section{School Meals}

\section{Environmental hygiene}

In B.A.O.R. school meals are subsidised and are prepared in well designed and properly equipped school kitchens; the quality and variety of meals generally is good. 
A school meals adviser was employed during the writer's tour of duty in B.A.O.R. and she did invaluable work in ensuring a high standard of nutrition and hygiene. The school doctor, as well as checking food hygiene should, on occasion, join in the meals with the pupils and teachers; this is one more way of improving relations generally and getting to know the pupils.

\section{School premises}

The doctor should inspect the premises periodically and in consultation with Army Health specialists should help the head teacher to achieve any necessary repairs or improvements related to health. Even in the most modern, newly built school, a major hygiene problem can occur. A case in point concerns a school in B.A.O.R. built in 1963. One year later, in the summer months, indoor dry bulb temperatures of $85^{\circ} \mathrm{F}$ and above were recorded frequently, when outside temperatures were well below this figure. The orientation of the school building was such that from mid-day the warm afternoon sun shone directly through large windows into most of the classrooms and the assembly hall. The windows were so constructed that, if opened to allow through ventilation, the protective curtains could not be closed to keep out direct sunlight. The solution was the erection of a special type of outdoor shop-window blind over each classroom affected, which made it possible to reduce glare and direct radiant heat and at the same time to open the windows to allow air movement and ventilation.

This example shows that excessive heat effects can be experienced in temperate climates. In passing it should be mentioned that German schools do not experience such effects since schools close about one o'clock daily. Pupils therefore complete the day's school work during the relatively cool morning and early afternoon.

\section{Future trends}

Clearly there is a requirement for school health services as long as service families continue to reside in overseas Commands (including B.A.O.R.) The need is accentuated by the constantly changing school populations; overseas tours are relatively short (two to three years) or even less in some cases. It is also possible for certain families to serve outside the United Kingdom continuously for up to five years or even longer. Many children will never have experienced the school health service in the United Kingdom or may have been examined by a school doctor only once.

Each school should have an appointed doctor and nurse. It is unlikely that all overseas stations will achieve full time school doctors. The prime requisite is to interest all service doctors in school health and their training in this respect may need revision. It has proved necessary to train R.A.M.C. doctors in family general practice therefore, in the writer's opinion, it is equally important to train them in school health. Such instruction should include visits to Local Education Authority schools and participation in school health work under supervision. Training should include the management of handicapped children, particularly ascertainment, registration and the methods of providing special educational treatment or training.

Finally, the whole system of ascertainment and placement of handicapped children, especially those mentally backward and maladjusted, should be reviewed. The system must be improved, firstly to ensure that all needy children are brought to light and secondly that the time interval between ascertainment and ultimate disposal is shortened. At present it may take a year or more to place a handicapped school child in a suitable 
educational or other special establishment. Perhaps service school children do not get a fair "crack of the whip" as regards being offered special places by certain Local Authorities in the United Kingdom?

\section{Summary}

This paper discusses school health schemes operated by the Services in B.A.O.R. and Hong Kong over a three year period.

Certain aspects of these schemes are described in detail because of differences in attitudes and approach, as compared with similar schemes operated in the United Kingdom under Local Education Authority arrangements.

The results of screening large numbers of service school children under the selective system are described.

Particular reference is made to handicapped children with accounts of two cases to emphasise difficulties peculiar to service life.

Reference is made to opportunities for research such as Heaf testing surveys and BCG vaccination by Dermo-jet.

A plea is made for a better system of training doctors to improve the quality of the health services provided for service school children overseas. It is recommended that the system of ascertainment and disposal of the handicapped should be improved so that such children can be provided with at least as good special education or special training as those normally permanently resident in the United Kingdom.

\section{REFERENCES}

Beaver, R. (1965). The Basic Requirements of a School Audiometric Service. J. roy. Inst. publ. Hlth, 28, 130.

Chief Medical Officer of the Department of Education \& Science (1964). Report for the years 1962 and 1963. The Health of the School Child. p. 1. H.M.S.O., London.

Peters, L. B. (1965). Two Experiments in the Selective Medical Examination of School Children. Publ. Hith. (Lond1), 59, 143.

Peters, L. B. (1966). Pers. Comm.

Power, J. G. P. (1967). Intradermal B.C.G. Vaccination by Dermo-jet. J. roy. Army med. Cps., $113,197$. TAYLOR, I. (1965). The Control of Infection at School. J. roy. Inst. publ. Hlth, $28,152$.

Williams, O. S. (1966). School Medical Examination of Young Children. J. roy. Army med. Cps, $112,194$. 